\title{
KAJIAN PENAMBAHAN ABU SEKAM PADI DARI BERBAGAI SUHU PENGABUAN TERHADAP PLASTISITAS KAOLIN
}

\author{
Sayidatul Ummah ${ }^{1}$, Anton Prasetyo ${ }^{1}$, Himmatul Barroroh ${ }^{1}$ \\ ${ }^{1}$ Jurusan Kimia, Fakultas Sains dan Teknologi \\ Universitas Islam Negeri (UIN) Maulana Malik Ibrahim Malang
}

\begin{abstract}
ABSTRAK
Abu sekam padi merupakan bahan buangan dari padi yang mengandung silika $\left(\mathrm{SiO}_{2}\right)$. Oleh karena itu abu sekam padi mempunyai peluang sebagai bahan aditif pada pembuatan keramik. Pembuatan abu sekam padi dilakukan pada variasi suhu pengabuan $600{ }^{\circ} \mathrm{C}, 700{ }^{\circ} \mathrm{C}$ dan $800{ }^{\circ} \mathrm{C}$ selama 4 jam. Hasil penelitian menunjukkan bahwa tingkat kecerahan warna dari abu sekam padi semakin tinggi seiring kenaikan suhu pengabuan $600{ }^{\circ} \mathrm{C}, 700{ }^{\circ} \mathrm{C}$ dan $800{ }^{\circ} \mathrm{C}$ yaitu 60,8; 61,4; 66,5. Kadar air dari abu sekam padi dari hasil pengabuan pada suhu $600{ }^{\circ} \mathrm{C}, 700{ }^{\circ} \mathrm{C}$ dan $800{ }^{\circ} \mathrm{C}$ sebesar 0,596\%; 0,895\%; dan 0,296 \%. Kadar karbon (termasuk kontribusi kadar air) dari masing-masing abu sekam padi sebesar 0,045\%; 0,048\%; 0,037\%, jumlah kualitatif $\mathrm{SiO}_{2}$ dari abu sekam padi hasil pengabuan pada suhu pengabuan 600 ${ }^{0} \mathrm{C}<700{ }^{\circ} \mathrm{C}<800{ }^{\circ} \mathrm{C}$ sedangkan komposisi kimia dari abu sekam padi yang dominan adalah Si hingga mencapai 91,2\%. Difraktogram dari masing-masing abu sekam padi menunjukkan pola difraksi sinar X dengan kristalinitas yang rendah dan cenderung amorf. Indeks plastisitas kaolin semakin turun dengan penambahan abu sekam padi yang diabukan pada variasi suhu $600{ }^{\circ} \mathrm{C}, 700{ }^{\circ} \mathrm{C}$ dan $800{ }^{\circ} \mathrm{C}$ yaitu; 21,49; 18,$45 ; 10,77$.
\end{abstract}

Kata Kunci: Abu Sekam Padi (ASP), plastisitas, kaolin.

\section{PENDAHULUAN}

Sekam padi adalah bagian terluar dari butir padi, yang merupakan hasil sampingan saat proses penggilingan padi dilakukan. Sekitar $20 \%$ dari bobot padi adalah sekam padi (Hara, 1986) dan $15 \%$ berat abu akan diperoleh dari total berat sekam padi yang dibakar (Chen et al, 1991). Abu sekam padi merupakan bahan buangan dari padi yang mempunyai sifat khusus yaitu mengandung senyawa kimia yang dapat bersifat pozolan, yaitu mengandung silika $\left(\mathrm{SiO}_{2}\right)$ (Herina, 2005). Nilai paling umum kandungan silika dari abu sekam adalah 94 - 96 $\%$ dan apabila nilainya mendekati atau di bawah $90 \%$ kemungkinan disebabkan oleh sampel sekam yang telah terkontaminasi dengan zat lain yang kandungan silikanya rendah (Houston, 1972).

Senyawa kimia silika $\left(\mathrm{SiO}_{2}\right)$ adalah suatu senyawa yang sangat luas aplikasinya mulai bidang konstruksi seperti bahan campuran untuk membuat keramik seni, semen, dan beton (Harsono, 2002). Pemanfaatan kandungan silika pada abu sekam padi dapat meningkatkan produksi material keramik tradisional. Dalam pembuatan keramik ada beberapa faktor yang mempengaruhi kualitas produk salah satu faktor tersebut adalah plastisitas. Jika nilai plastisitas bahan keramik mentah tidak diketahui dengan tepat, maka produk keramik yang halus tidak dihasilkan karena adanya keretakan, perubahan bentuk atau aneka cacat pada saat proses pembuatannya (Abdullah, 2004).

Plastisitas yaitu kemampuan tanah dalam menyesuaikan perubahan bentuk atau volume tanpa terjadinya retak-retak yang disebabkan oleh penyerapan air di sekeliling permukaan partikel lempung (Muntohar, 2007). Apabila abu sekam padi yang mengandung silika oksida ditambahkan pada lempung kaolin maka akan mempengaruhi nilai plastisitasnya, sehingga dilakukan kajian penambahan abu sekam padi dari berbagai suhu pengabuan terhadap plastisitas kaolin untuk mengetahui karakterisasi abu sekam padi dari berbagai suhu pengabuan serta untuk mengetahui nilai indeks plastisitas dari kaolin. 


\section{Eksperimen}

\subsection{Bahan Penelitian}

Sampel sekam padi diambil dari daerah Sendang Kediri. Lempung kaolin berasal dari pengrajin keramik daerah Dinoyo, Malang. Bahan kimia berupa $\mathrm{K}_{2} \mathrm{Cr}_{2} \mathrm{O}_{7}, \mathrm{H}_{2} \mathrm{SO}_{4}$ dan aquades

\subsection{Alat Penelitian}

Alat yang digunakan dalam penelitian ini adalah labu ukur $25 \mathrm{~mL}$, pipet ukur $5 \mathrm{~mL}$, gelas beaker $100 \mathrm{~mL}$, ayakan ukuran 40 mesh, desikator, tanur (Thermo Scientific), timbangan analitik, oven, spatula, cawan penguap, spektrofotometer (Thermo Scientific), Color Reader, seperangkat alat atterberg, seperangkat alat pelet, seperangkat alat FTIR (Shimadzu), seperangkat instrument XRF (MiniPal4) dan seperangkat instrument XRD (Philips X'pert)

\subsection{Prosedur Penelitian}

Sekam padi dibersihkan dan dicuci dengan air kemudian dikeringkan di bawah sinar matahari. Sekam padi kemudian dioven pada suhu $300{ }^{0} \mathrm{C}$ selama 30 menit (Harsono, 2002). Arang yang dihasilkan diabukan pada variasi suhu pengabuan $600{ }^{\circ} \mathrm{C}, 700^{\circ} \mathrm{C}$, dan 800 ${ }^{0} \mathrm{C}$ selama 4 jam (Aina, 2007). Karakterisasi abu sekam padi yang dihasilkan meliputi analisa warna dengan Color Reader, penentuan kadar karbon dengan spektrofotometer, identifikasi kualitatif jumlah silika dengan FTIR, komponen kimia dari abu sekam padi menggunakan X-Ray Fluorencence (XRF MiniPal4), serta kristalinitas dari abu sekam padi dikarakterisasi dengan $X$-Ray Difraction (XRD Philips X'pert). Uji plastisitas dari campuran $5 \mathrm{~g}$ abu sekam dari hasil pengabuan pada suhu $600{ }^{\circ} \mathrm{C}, 700{ }^{\circ} \mathrm{C}$ dan $800{ }^{\circ} \mathrm{C}$ dengan $50 \mathrm{~g}$ kaolin dengan metode Atterberg. Uji batas cair dilakukan dengan memasukkan pasta campuran kaolin-abu sekam padi dari masingmasing hasil pengabuan ke dalam mangkuk pada alat atterberg, kemudian mengalur dan dihitung jumlah ketukan serta dihitung kadar airnya. Uji batas plastis pada pasta campuran dilakukan dengan mengulung-gulung hingga pasta mengalami retak-retak pada diameter $\pm 3 \mathrm{~mm}$.

\section{Pembahasan}

\subsection{Karakterisasi Abu Sekam Padi}

a. Warna

Analisa warna pada abu sekam padi dari variasi suhu pengabuan $600{ }^{0} \mathrm{C}, 700{ }^{0} \mathrm{C}$ dan $800{ }^{\circ} \mathrm{C}$ dilakukan dengan Color Reader (CR 10). Parameter L pada Color Reader menunjukkan tingkat kecerahan dari sampel dan nilainya berkisar dari $0=$ gelap dan $100=$ terang, $a^{*}$ menunjukkan warna jingga sampai merah sedangkan $b^{*}$ menunjukkan warna kuning sampai biru. Berdasarkan hasil penelitian menunjukkan bahwa dengan kenaikan suhu pengabuan $600{ }^{\circ} \mathrm{C}, 700{ }^{\circ} \mathrm{C}$ dan $800{ }^{\circ} \mathrm{C}$ tingkat kecerahan dari abu sekam padi semakin besar yaitu 60,8; 61,4; 66,5.

Menurut Azis (dalam Purwandari, 2006) pengabuan pada temperatur tinggi akan menghasilkan silika berwarna merah muda dengan bentuk silika kristobalit dan tridimit serta sedikit sekali yang berbentuk kuarsa. Pengabuan pada temperatur rendah menghasilkan abu sekam berwarna kelabu dan berstruktur amorf atau tidak teratur.

\section{b. Kadar Karbon}

Penentuan kadar karbon dengan spektrofotometer dari abu sekam padi pada panjang gelombang 561 termasuk kontribusi kadar air diperoleh kadar karbon sebesar 0,045 $\% ; 0,048 \%$ dan $0,037 \%$. Berdasarkan persamaan di bawah:

Kadar C (\%) = ppm kurva $\times$ L ekstrak $\times 100 \%$ $x \mathrm{mg} \mathrm{sampel}^{-1} x \mathrm{fk}$ 


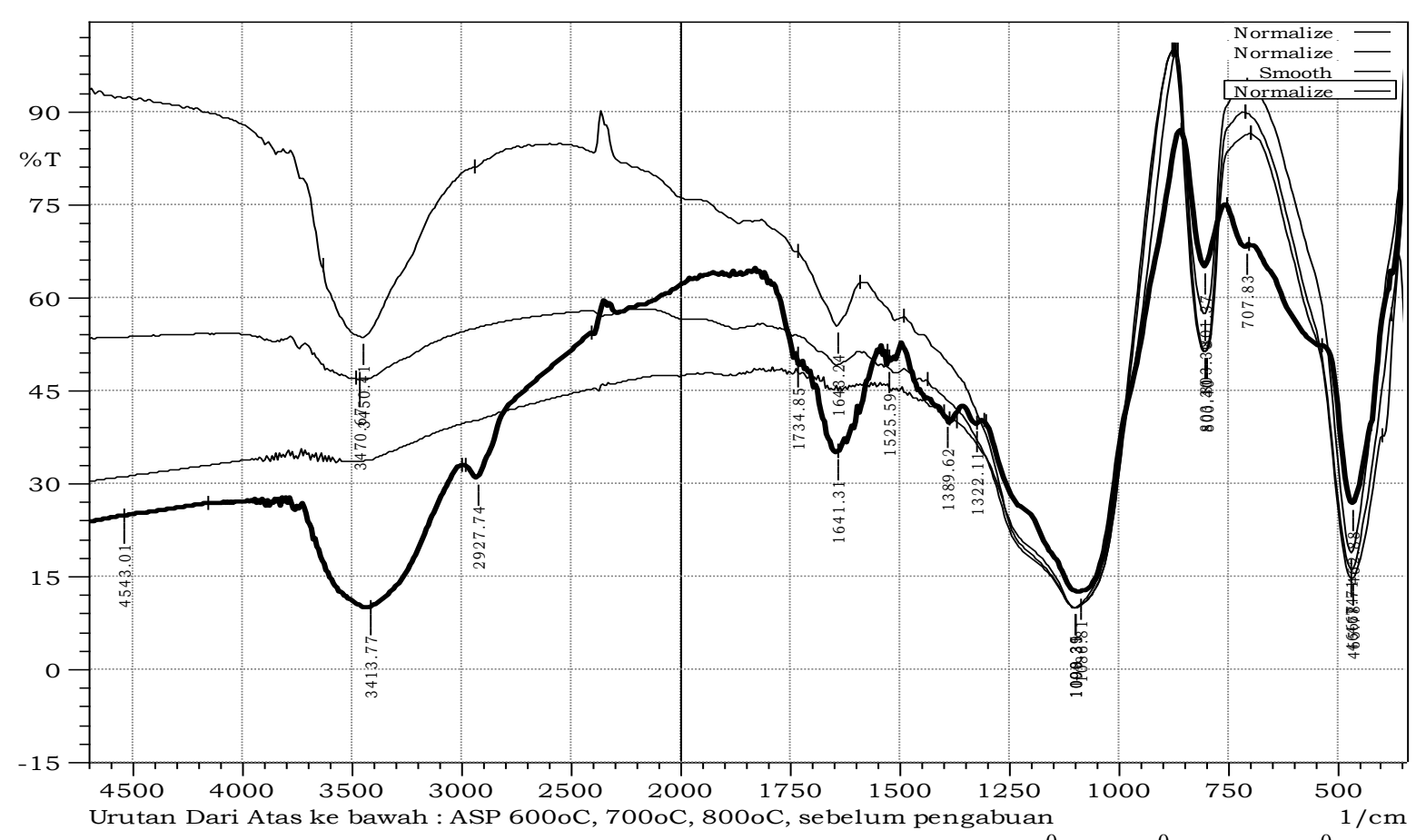

Gambar 1. Spektra Sekam Padi dan hasil pengabuan pada suhu $600{ }^{\circ} \mathrm{C}, 700{ }^{\circ} \mathrm{C}$ dan $800{ }^{\circ} \mathrm{C}$

Hasil kadar karbon dari abu sekam padi yang diabukan pada suhu $700{ }^{\circ} \mathrm{C}$ lebih besar daripada abu sekam padi dari hasil pengabuan $600{ }^{\circ} \mathrm{C}$ dan $800{ }^{\circ} \mathrm{C}$. Penentuan kadar karbon dipengaruhi dari koreksi faktor kadar air, dimana semakin besar kadar air maka semakin besar pula kadar airnya. Hal ini dimungkinkan air yang terdapat pada abu sekam padi bereaksi dengan karbondioksida yang terlarut pada air sehingga terbentuk karbonat yang mengandung karbon, sehingga kadar karbon yang diterhitung merupakan kadar karbon semu atau tidak sesungguhnya dari abu sekam padi hasil pengabuan pada suhu $600{ }^{\circ} \mathrm{C}, 700{ }^{\circ} \mathrm{C}$ dan $800{ }^{\circ} \mathrm{C}$.

\section{c. Identifikasi Kualitatif Jumlah}

Identifikasi kualitatif jumlah silika dengan FTIR dari masing-masing abu sekam padi yang diabukan pada suhu pengabuan 600 ${ }^{0} \mathrm{C}, 700{ }^{\circ} \mathrm{C}$ dan $800{ }^{\circ} \mathrm{C}$ menunjukkan spektra khas dari silika. Jumlah kualitatif $\mathrm{SiO}_{2}$ dari abu sekam padi hasil pengabuan pada suhu pengabuan $600{ }^{0} \mathrm{C}<700{ }^{0} \mathrm{C}<800{ }^{0} \mathrm{C}$. Perbandingan spektra sekam padi dan abu sekam padi ditunjukkan pada gambar 1 .

Seiring kenaikan suhu pengabuan pada sekam padi terlihat spektra silika terbentuk sempurna sedangkan serapan karbon dan gugus -OH semakin hilang. Hal ini karena dengan kenaikan suhu pengabuan senyawa karbon dan gugus - $\mathrm{OH}$ menguap membentuk senyawa karbondioksida dan air pada proses pengabuan.

\section{d. Identifikasi Komponen Kimia}

Komponen kimia dari abu sekam padi hasil pengabuan pada suhu $600{ }^{\circ} \mathrm{C}, 700{ }^{\circ} \mathrm{C}$ dan $800{ }^{\circ} \mathrm{C}$ dengan XRF ditunjukkan pada tabel di bawah ini:

Tabel 1. Komponen Kimia ASP

\begin{tabular}{|c|c|}
\hline Unsur & Kandungan (\%) \\
\hline $\mathrm{Si}$ & 91,23 \\
\hline $\mathrm{K}$ & 4,72 \\
\hline $\mathrm{Ca}$ & 2,786 \\
\hline $\mathrm{Mn}$ & 0,58 \\
\hline $\mathrm{Fe}$ & 0,283 \\
\hline $\mathrm{Cu}$ & 0,063 \\
\hline $\mathrm{Eu}$ & 0,256 \\
\hline $\mathrm{Ni}$ & 0,02 \\
\hline $\mathrm{Zn}$ & 0,007 \\
\hline $\mathrm{Re}$ & 0,115 \\
\hline
\end{tabular}




\section{e. Kristalinitas}

Karakterisasi abu sekam padi dengan XRD untuk mengetahui kristalinitas dari hasil pengabuan pada suhu $600{ }^{\circ} \mathrm{C}, 700{ }^{\circ} \mathrm{C}$ dan 800 ${ }^{0} \mathrm{C}$. Hasil difraktogram dari masing-masing hasil pengabuan sekam padi menunjukkan pola difraksi yang hampir sama. Difraktogram hasil XRD menunjukkan pola difraksi dengan kristalinitas yang rendah dan cenderung amorf. Difraktogram dari abu sekam padi hasil pengabuan pada suhu $600{ }^{\circ} \mathrm{C}, 700{ }^{0} \mathrm{C}$ dan 800 ${ }^{0} \mathrm{C}$ ditunjukkan pada gambar di bawah ini:

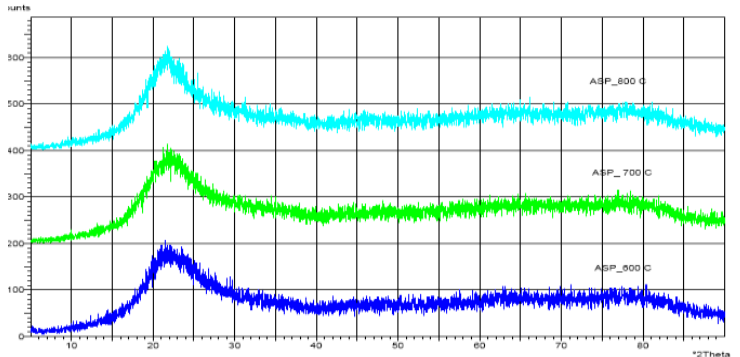

Gambar 2. Difraktogram ASP $600{ }^{\circ} \mathrm{C}$ (biru tua), ASP $700{ }^{0} \mathrm{C}$ (hijau), ASP $800{ }^{0} \mathrm{C}$ (biru muda)

\section{f. Penentuan Indeks Plastisitas}

Indeks plastisitas merupakan selisih dari batas cair/LL (liquid limit) dan batas plastis/PL (plastic limit). Plastisitas disebabkan oleh adanya partikel mineral lempung dalam tanah. Plastisitas tanah pada dasarnya disebabkan karena penyerapan air disekeliling partikel lempung ke permukaan partikel. Berdasarkan hasil penelitian didapat indeks plastisitas kaolin dan campuran kaolin-abu sekam padi sebagai berikut:

Tabel 2. Hasil Indeks Plastisitas

\begin{tabular}{|c|l|c|c|c|}
\hline No & \multicolumn{1}{|c|}{ Sampel } & LL \% & PL \% & PI \% \\
\hline 1 & Kaolin & 55,67 & 28,18 & 27,49 \\
\hline 2 & $\begin{array}{l}\text { K-ASP } \\
600^{\circ} \mathrm{C}\end{array}$ & 52,24 & 30,75 & 21,49 \\
\hline 3 & $\begin{array}{l}\text { K-ASP } \\
700^{\circ} \mathrm{C}\end{array}$ & 46,70 & 28,25 & 18,45 \\
\hline 4 & $\begin{array}{l}\text { K-ASP } \\
800^{\circ} \mathrm{C}\end{array}$ & 37,55 & 26,78 & 10,77 \\
\hline
\end{tabular}

Keterangan: K-ASP (Kaolin-Abu Sekam Padi)
Berdasarkan tabel 2 dapat diketahui bahwa dengan penambahan $5 \mathrm{~g}$ atau $10 \%$ abu sekam padi dari hasil pengabuan pada suhu 600 ${ }^{0} \mathrm{C}, 700{ }^{\circ} \mathrm{C}$ dan $800{ }^{\circ} \mathrm{C}$ indeks plastisitas kaolin mengalami penurunan. Hal ini menurut Yuniarti, dkk (2008: 42) dalam penelitiannya menyebutkan bahwa penambahan abu sekam padi yang mengandung silika dan alumina yang bercampur dengan air akan terbentuk pasta. Sehingga rongga - rongga pori yang dikelilingi bahan tersebut lebih sedikit menyerap air.

\section{KESIMPULAN}

Tingkat kecerahan warna dari abu sekam padi semakin tinggi seiring kenaikan suhu pengabuan $600{ }^{0} \mathrm{C}, 700{ }^{\circ} \mathrm{C}$ dan $800{ }^{\circ} \mathrm{C}$ yaitu 60,$8 ; 61,4 ; 66,5$. Kadar air abu sekam padi dari hasil pengabuan pada suhu $600{ }^{\circ} \mathrm{C}, 700{ }^{\circ} \mathrm{C}$ dan $800{ }^{\circ} \mathrm{C}$ sebesar 0,596\%; 0,895\%; dan $0,296 \%$. Kadar karbon (termasuk kontribusi kadar air) dari masing-masing abu sekam padi sebesar $0,045 \% ; 0,048 \% ; 0,037 \%$, jumlah kualitatif $\mathrm{SiO}_{2}$ dari abu sekam padi hasil pengabuan pada suhu pengabuan $600{ }^{\circ} \mathrm{C}<700$ ${ }^{0} \mathrm{C}<800{ }^{\circ} \mathrm{C}$, untuk komposisi kimia dari abu sekam padi yang dominan adalah $\mathrm{Si}$ hingga mencapai 91,2 \%. Difraktogram dari masingmasing abu sekam padi menunjukkan pola difraksi sinar $\mathrm{X}$ dengan kristalinitas yang rendah dan cenderung amorf. Indeks plastisitas kaolin semakin turun dengan penambahan abu sekam padi yang diabukan pada variasi suhu $600{ }^{\circ} \mathrm{C}, 700{ }^{\circ} \mathrm{C}$ dan $800{ }^{\circ} \mathrm{C}$ yaitu; 21,$49 ; 18,45$; 10,77 . 


\section{DAFTAR PUSTAKA}

Abdulloh. 2004. Evaluasi Teknik Uji Geser dan Uji Tekan dalam Kajian Pengaruh Kadar Air dan Penambahan Zai Imbuh Terhadap Karakteristik Plastisitas Lempung Asal Dsn. Pandisari Ds Sawo Kec. Kutorejo Kab. Mojokerto. Tesis. Tidak diterbitkan. Bandung: Fakultas MIPA ITB.

Chen, J-M and Chang, F-W. 1991. The Chlorination Kinetics of Rice Hull, Ind. Eng. Chem. Res.

Hara. 1986. Utilization of Agrowastes for Buildinng Materials. Japan: International Research and Development Cooperation Division, AIST, MITI.

Harsono, H. 2002. Pembuatan Silika Amorf dari Limbah Sekam Padi (Syntesis of Amorphous Silicon from Outer Shell of Rice Seeds). Jurnal Ilmu Dasar. Vol. 3 No.2, 2002: 98-103 98.

Herina, S. 2005. Kajian Pemanfaatan Abu Sekam Padi Untuk Stabilisasi Tanah Dalam Sistem Pondasi di Tanah Ekspansif. Kolokium dan Open House. Bandung: Pusat Penelitian dan Perkembangan Permukiman Badan Penelitian dan Pengembangan Departemen Pekerjaan Umum 8 - 9 Desember 2005.

Muntohar, A.S. 2007. Pengantar Rekayasa geoteknik.http://muntohar.files.wordpre ss.com/2007/04/sample-

bab3.pdf.Diakses pada tanggal 31 Juli 2009.

Yuniarti, R., Suarini, G.A., Ismawati. 2008. Perbandingan Nilai Daya Dukung Tanah Dasar Badan Jalan yang Distabilisasi Semen dan Abu Sekam Padi. Media Teknik Sipil. Lombok: Jurusan Teknik Sipil Universitas Mataram, Januari 2008. 